Gif-sur-Yvette

See Sa (Saclay), page 140.

\title{
Geochronological Laboratory
}

\begin{tabular}{|c|c|c|c|c|c|}
\hline $\begin{array}{l}\text { Laboratory } \\
\text { number }\end{array}$ & $\begin{array}{l}\text { Published } \\
\text { reference }\end{array}$ & $\begin{array}{l}\text { Original date or } \\
\text { other value }\end{array}$ & $\begin{array}{l}\text { Corrected date } \\
\text { or other value }\end{array}$ & $\partial \mathrm{C}^{14}, \%$ & $\begin{array}{l}\text { A.D./ } \\
\text { B.C. date }\end{array}$ \\
\hline GL-5 & $98: 195$ & $3270 \pm 110$ & & & 1320 B.C. \\
\hline-6 & 98:195 & $4100 \pm 150$ & & & 2150 B.C. \\
\hline-7 & $98 a: 4$ & $2230 \pm 110$ & & & 280 B.C. \\
\hline-8 & $98 a: 4$ & $2020 \pm 110$ & & & 70 B.C. \\
\hline-10 & $98 a: 4$ & $2120 \pm 110$ & & & 170 B.C. \\
\hline-12 & $98 a: 5$ & $3170 \pm 110$ & & & 1220 B.C. \\
\hline-17 & $98 a: 5$ & $4000 \pm 110$ & & & 1900 B.C. \\
\hline-18 & $98 a: 5$ & $4650 \pm 110$ & & & 2700 B.C. \\
\hline-19 & $98 a: 3$ & $1240 \pm 80$ & & & A.D. 710 \\
\hline$-23^{1}$ & $98 a: 3$ & $950 \pm 80$ & & & A.D. 1000 \\
\hline-24 & $98: 195$ & $5210 \pm 110$ & & & 3260 B.C. \\
\hline-25 & $98: 195$ & $1940 \pm 80$ & & & A.D. 10 \\
\hline-27 & $98 a: 7$ & $9720 \pm 140$ & & & 7770 B.C. \\
\hline-28 & $98: 196$ & $8200 \pm 200$ & & & 6250 B.C. \\
\hline-30 & $98: 195$ & $3210 \pm 100^{2}$ & & & 1260 B.C. \\
\hline-33 & $99: 1^{3}$ & $3510 \pm 110$ & $3510 \pm 95 c$ & & 1560 B.C. \\
\hline-36 & $99: 2$ & $8390 \pm 200$ & $8390 \pm 150 c$ & & 6440 B.C. \\
\hline-37 & $99: 1$ & $1350 \pm 60$ & & & A.D. 600 \\
\hline-38 & $98: 196$ & $7800 \pm 160$ & & & 5850 B.C. \\
\hline-39 & $99: 2$ & $8770 \pm 150$ & & & 6820 B.C. \\
\hline-40 & $99: 2$ & $8690 \pm 150$ & & & 6740 B.C. \\
\hline-41 & $99: 2$ & $8670 \pm 150$ & & & 6720 B.C. \\
\hline-42 & $99: 2$ & $8700 \pm 200$ & & & 6750 B.C. \\
\hline-43 & $99: 2$ & $8895 \pm 150$ & & & 6945 B.C. \\
\hline-44 & $99: 2$ & $6650 \pm 170$ & $6650 \pm 120 c$ & & 4700 B.C. \\
\hline-45 & $99: 2$ & $6570 \pm 165$ & $6670 \pm 120 \mathrm{c}$ & & 4720 B.C. \\
\hline-46 & $99: 2$ & $7300 \pm 200$ & & & 5350 B.C. \\
\hline-47 & $99: 1$ & $1965 \pm 80$ & & & 15 B.C. \\
\hline-48 & $99: 2$ & $6930 \pm 180$ & $6930 \pm 120 c$ & & 4980 B.C. \\
\hline$-4,9$ & $99: 2$ & $6300 \pm 160$ & $6300 \pm 180 c$ & & 4350 B.C. \\
\hline-50 & $99: 2$ & $6750 \pm 170$ & $6750 \pm 120 c$ & & 4800 B.C. \\
\hline-52 & $99: 1$ & $3360 \pm 150$ & $3360 \pm 90 c$ & & 1410 B.C. \\
\hline-53 & $99: 1$ & $2030 \pm 85$ & & & 80 B.C. \\
\hline-54 & $99: 3$ & $>50,000$ & & & \\
\hline$-55^{4}$ & $99: 3$ & $10,750 \pm 300$ & $10,750 \pm 180 \mathrm{c}$ & & 8800 B.C. \\
\hline-56 & $99: 1$ & $3370 \pm 115$ & $3370 \pm 90 c$ & & 1420 B.C. \\
\hline
\end{tabular}

${ }^{1}$ Cross-check sample $=$ Gro -16 .

${ }^{2}$ Reference 99 gives only the 2nd count of this sample, $3270 \pm 80$; both have been averaged by the editors.

${ }^{3}$ Dates in Reference 99 (circulated with lab. code-designation $F$ ) have been corrected by J. M. Sheldon, Inst. of Archeol., Univ. of London, by reference to the Ph.D. thesis (1958) of D E Vaughan It is not certain that any GL dates have been corrected for a Suess effect in the standard ("contemporary wood" according to Crathorn, 1953, Nature, v 172, p. 632).

${ }^{4}$ Cross-check sample $=$ K-101. 